\title{
Motivating HIV Providers in Vietnam to Learn: A Mixed-Methods Analysis of a Mobile Health Continuing Medical Education Intervention
}

Anna Larson Williams ${ }^{1}$, MPH; Andrew Hawkins ${ }^{1}$, BA; Lora Sabin ${ }^{1}$, MA, PhD; Nafisa Halim ${ }^{1}$, PhD; Bao Le Ngoc ${ }^{2}$, MA; Viet Ha Nguyen ${ }^{2}$, MA; Tam Nguyen ${ }^{3}$, MA; Rachael Bonawitz ${ }^{1}$, MD; Christopher Gill ${ }^{1}$, MS, MD

\footnotetext{
${ }^{1}$ Department of Global Health, Boston University School of Public Health, Boston, MA, United States

${ }^{2}$ Consulting, Researching on Community Development, Hanoi, Vietnam

${ }^{3}$ Center for Population Research Information and Databases, General Office for Population and Family Planning, Vietnam Ministry of Health, Hanoi, Vietnam
}

\section{Corresponding Author:}

Anna Larson Williams, MPH

Department of Global Health

Boston University School of Public Health

801 Massachusetts Avenue

3rd Floor

Boston, MA, 02118

United States

Phone: 16176385234

Email: alarsonw@bu.edu

\section{Abstract}

Background: The Mobile Continuing Medical Education Project (mCME V.2.0) was a randomized controlled trial designed to test the efficacy of a text messaging (short message service [SMS])-based distance learning program in Vietnam that included daily quiz questions, links to readings and online courses, and performance feedback. The trial resulted in significant increases in self-study behaviors and higher examination scores for intervention versus control participants.

Objective: The objective of this mixed-methods study was to conduct qualitative and quantitative investigations to understand participants' views of the intervention. We also developed an explanatory framework for future trial replication.

Methods: At the endline examination, all intervention participants completed a survey on their perspectives of mCME and self-study behaviors. We convened focus group discussions to assess their experiences with the intervention and attitudes toward continuing medical education.

Results: A total of 48 HIV specialists in the intervention group completed the endline survey, and 30 participated in the focus group discussions. Survey and focus group data suggested that most clinicians liked the daily quizzes, citing them as convenient mechanisms to convey information in a relevant manner. A total of 43 of the 48 (90\%) participants reported that the daily quizzes provided motivation to study for continuing medical education purposes. Additionally, 83\% (40/48) of intervention participants expressed that they were better prepared to care for patients with HIV in their communities, compared with 67\% (32/48) at baseline. Participation in the online coursework component was low (only 32/48, 67\% of intervention participants ever accessed the courses), but most of those who did participate thought the lectures were engaging $(26 / 32,81 \%)$ and relevant $(29 / 32,91 \%)$. Focus group discussions revealed that various factors influenced the clinicians' decision to engage in higher learning, or "lateral learning," including the participant's availability to study, professional relevance of the topic area, and feedback. These variables serve as modifying factors that fit within an adapted version of the health belief model, which can explain behavior change in this context.

Conclusions: Qualitative and quantitative endline data suggested that mCME V.2.0 was highly acceptable. Participant behaviors during the trial fit within the health belief model and can explain the intervention's impact on improving self-study behaviors. The mCME platform is an evidence-based approach with the potential for adoption at a national scale as a method for promoting continuing medical education.

Trial Registration: ClinicalTrials.gov NCT02381743; https://clinicaltrials.gov/ct2/show/NCT02381743 
(JMIR Med Educ 2019;5(1):e12058) doi: 10.2196/12058

\section{KEYWORDS}

continuing medical education; HIV/AIDS; mHealth; Vietnam; health education; SMS intervention; telemedicine; text messaging

\section{Introduction}

\section{Background}

Continuing medical education (CME) is essential to maintaining the competence of a clinical workforce, but the complexity of managing CME programs and the resources required can be barriers to implementation. This may be particularly true in low- and middle-income countries. In November 2009, Vietnam passed the Law on Medical Examination and Treatment, which mandated that all clinicians participate in yearly CME activities to maintain licensure [1-3]. There has been increasing enthusiasm for mobile health (mHealth) in Vietnam, with 20 initiatives identified in a recent landscape analysis [4]. While this indicates an interest in using mHealth to improve the quality of health care through provider education, a lack of sustainability for current initiatives and absence of technological infrastructure pose challenges to mHealth programs across the country [4]. Since there is little infrastructure in the country to support such a national CME program, health officials may want to consider developing a feasible, scalable, and cost-effective platform that provides medical professionals with evidence-based training. Previous research in other contexts suggests that CME delivered at a distance is acceptable and can be effective at improving medical knowledge, changing behavior, and advancing clinical practice [5-15]. Distance learning is an attractive alternative to in-person CME, but evidence of its effectiveness is needed prior to program implementation at a national level.

Beginning in 2014, researchers at the Boston University School of Public Health, in Boston, MA, USA, collaborated with the Vietnamese Ministry of Health and the Vietnamese nongovernmental organization Consulting, Researching on Community Development to create the Mobile Continuing Medical Education Project (mCME). mCME was a short message service (SMS) text messaging-based mHealth education strategy that delivered CME via cell phones. Over 2 consecutive randomized controlled trials, we demonstrated that the mCME strategy was technically feasible, acceptable, and effective at motivating self-study behaviors, and it led to improved medical knowledge on a standardized examination [16-19].

Analysis of qualitative findings from the first mCME trial (V.1.0), which demonstrated feasibility and acceptability but not improved medical knowledge, influenced the design of V.2.0, which did demonstrate improved medical knowledge. During the design of V.2.0, mCME was considered a behavioral change intervention, and not a knowledge transfer intervention, with the emphasis on self-study behaviors. We enhanced the design to maximize study participation and engagement with the different intervention components. As we analyzed the results of mCME V.2.0, we noted that the fundamental components of the intervention were a pedagogical analog to the health belief model (HBM), a sociobehavioral theory that explains individual motivation to change behavior [20]. The
HBM employs perceived susceptibility and perceived severity to rely on cues to action to encourage behavior change [20,21]. We posit that the intervention is aligned with the HBM because of the way that mCME spurred increased self-study, acquisition of evidence-based resources, and professional collaboration during its implementation.

\section{Objective}

We aimed to analyze both qualitative and quantitative data obtained from participants randomly assigned to the mCME V.2.0 intervention to better understand the underlying mechanisms that led to successful increases in self-study behaviors and medical knowledge. We propose that understanding how the program worked will be critical to replicating its success at a national scale. We sought to understand how a digital education framework corresponding to the sociobehavioral HBM and designed to stimulate deeper learning could explain the success of the mCME approach. From within this framework, we used qualitative and quantitative data to evaluate (1) how medical professionals felt about the principal components in the intervention, and (2) the impacts that the intervention had on participants' self-study, knowledge, and self-efficacy.

\section{Methods}

\section{Study Site and Participants}

Full details of the mCME V.2.0 project methodology are published in the main effects article [18]. Briefly, mCME V.2.0 was a randomized controlled trial conducted in 2016-2017 that aimed to test whether an integrative model of SMS text messaging and Web-based learning could improve medical knowledge among Vietnamese HIV clinicians. HIV health professionals from 3 provinces in northern Vietnam (Thái Nguyên, H i Phòng, and Qu ng Ninh) were enrolled in the study and took a baseline examination (1 held in each province) to assess medical knowledge and then randomly assigned into intervention and control groups. The intervention group received the following: a daily multiple-choice quiz question pertaining to a specific module within the Hanoi Medical University (HMU) online courses, daily linked readings to additional information, regular reminders to access the HMU online courses, and feedback on their individual performance versus their peers' performance. The control group had access to the HMU courses and received nonmedical SMS text messages, but did not receive the daily medical quizzes, linked readings, feedback, or reminders to take the HMU courses. Multimedia Appendix 1 depicts the study design.

\section{Data Collection}

At the end of 6 months, both intervention and control groups took an endline examination to test for improvement in medical knowledge and completed a survey on their study behaviors and experiences with the trial. The 50-question survey covered 
topics such as study behaviors, experiences with each of the intervention components, attitudes toward CME, job satisfaction, and perception of HIV knowledge and skills. After the endline examination workshops at each of the 3 sites, study investigators in Vietnam scanned the quantitative surveys with an optical scanning device (Scantron, Inc, Eagan, MN, USA).

After the endline examination, we invited a subset of intervention participants from each of the 3 provinces to participate in focus group discussions (FGDs) to learn about their experiences with the intervention. Within each group, we attempted to include a balanced representation of experiences with the intervention, with roughly equal numbers of participants whose response rates of the daily quiz questions were above the median, and those whose response rates were below the median. We used quiz response rates for this stratification because the daily quizzes were the most fundamental core element of the mCME intervention. Following a semistructured FGD guide, we asked participants about their experiences with the intervention, the impact the intervention had on their learning, and their suggestions for how to improve the mCME approach. All 3 FGDs were recorded in Vietnamese and translated and transcribed into English.

\section{Data Analysis}

Boston University researchers analyzed the FGD transcripts in NVivo version 11 (QSR International). Themes and subthemes were individually identified and cross-checked by 2 qualitative analysts to test for variability, and then a consensus of key themes was reached prior to analysis. Responses were grouped and prioritized by frequency. We also compared responses by study site. Boston University researchers analyzed the survey data with various descriptive data analysis techniques using SAS version 9.4 (SAS Institute). As a secondary analysis, we analyzed qualitative and quantitative responses based on use of the intervention components (eg, we included survey results data on perspectives on the HMU courses only if the participant ever accessed the HMU courses). We include those results in this paper, to account for social desirability bias.

\section{Developing the Theoretical Framework to Understand Views on and Impact of the Intervention}

In a preliminary review of the data, we realized that there were several themes from the qualitative data that paralleled the HBM. The first component of both the HBM and our intervention is cues to action, which the HBM states provide a stimulus to trigger a decision or behavior change [20,21]. Another way in which this intervention mirrors HBM is through the idea of perceived severity and susceptibility; the HBM defines these as the individual's own perceptions of the likelihood of getting a disease or having a severe form of the disease [20,21]. We have applied this concept beyond the context of disease; in this intervention, perceived severity and susceptibility correspond to the perceived importance and level of need to take CME to provide high-quality medical care. In our intervention, these views were informed by several modifying variables that affected quality and intensity of learning among the participants. We analyzed how participants chose to access and use high-quality educational materials beyond the daily SMS text messages, which we termed lateral learning. We then developed a framework to explain the clinician's decision to learn through a behavioral lens (Figure $1[20,21])$. We analyzed the qualitative data within the context of this framework to explore how clinicians interacted with the intervention and to understand how lateral learning could be achieved.

The cues to action in $\mathrm{mCME}$ are the various text message interactions that the user has with the $\mathrm{mCME}$ program: the daily SMS quizzes, which prompt the user to seek an answer to a medical question; the HMU course reminders, which come at the beginning and end of each module; and individual and peer feedback, which comes in the form of a correct versus incorrect response per daily quiz question and an end-of-module final score comparing the individual's percentage correct responses compared with the rest of the cohort. Whether the cues to action led to lateral learning depended on the individual's weighing of the perceived susceptibility and perceived severity, which are modified by factors such as professional relevance, convenience of CME, perceived quality of resources, subject matter expertise, motivation and self-efficacy, technical literacy, and the participant's time and availability. These factors should be considered together with the HBM's concept of perceived susceptibility, or in this case, the perceived level of need for the individual to have CME, and the perceived severity, or in this context, the level of importance the individual places on CME. The individual then weighs the perceived prohibitive and supportive factors and determines whether to engage in lateral learning. Because a participant might choose to access vetted materials or additional resources of varying quality, we hypothesize that the educational value of outside resources is an additional moderating variable for lateral learning.

\section{Ethical Review}

This study was registered on ClinicalTrials.gov (NCT02381743) with ethical oversight by Boston University Medical Center, Boston, MA, USA, and Hanoi University of Public Health, Hanoi, Vietnam. All participants in this trial provided written informed consent prior to participation in the trial, with additional consent provided for participation in the FGDs. 
Figure 1. Framework for the decision to engage in lateral learning. Elements of the Mobile Continuing Medical Education Project are analogous to the health belief model. The figure illustrates the underlying behavioral mechanisms that lead a clinician to decide whether to engage in lateral learning, defined as accessing and using high-quality educational materials beyond daily short message service (SMS) text messages. CME: continuing medical education; HMU: Hanoi Medical University.

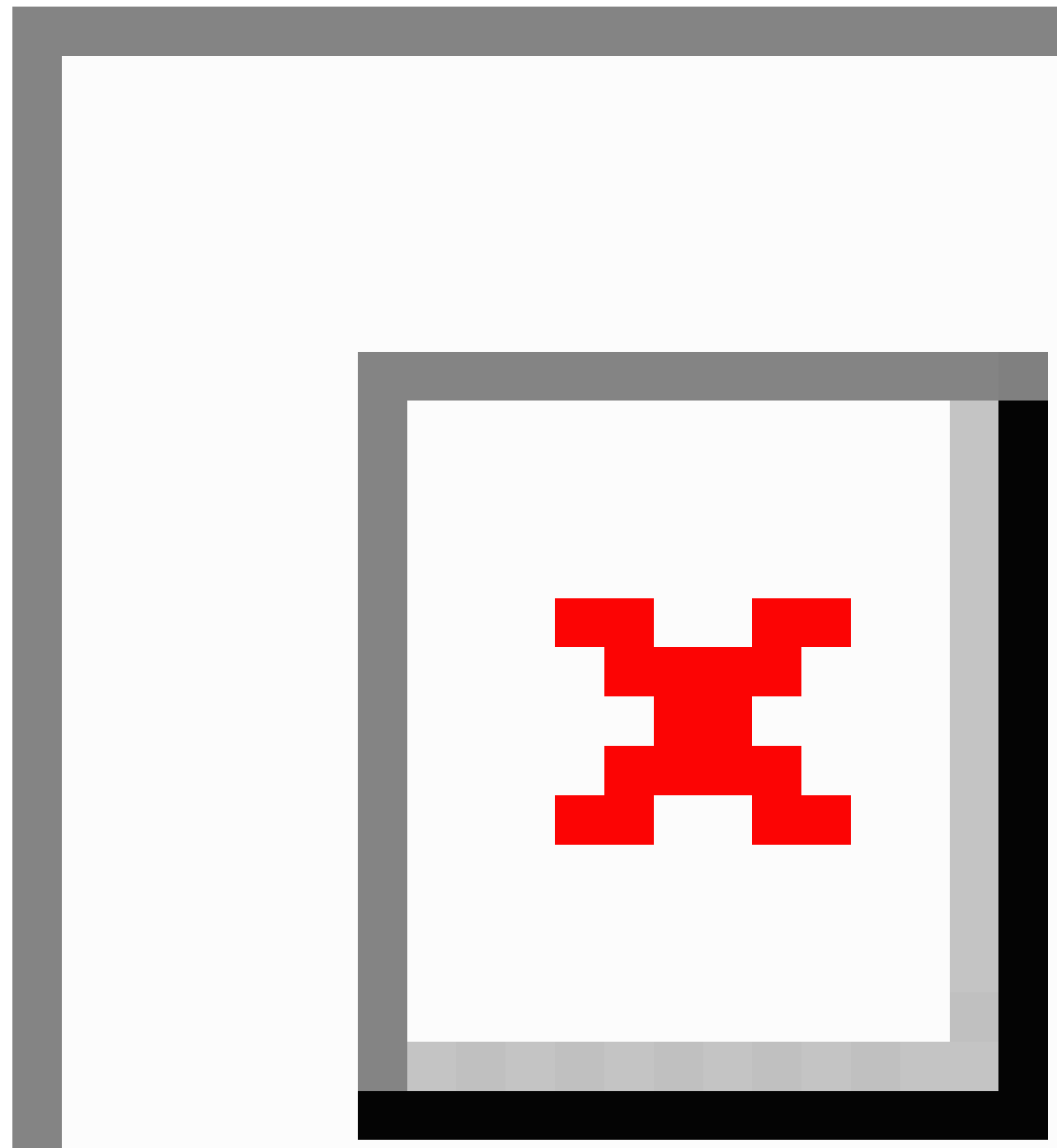

\section{Results}

\section{Background Characteristics of mCME V.2.0 Trial Participants}

Endline examinations with postintervention surveys and FGDs took place in May 2017. All HIV clinicians who participated in the intervention and returned for the endline examination were asked to complete the survey $(n=48)$. We asked 10 clinicians assigned to the intervention group at each of the 3 sites to participate in the FGDs $(n=30)$, all of whom signed a separate consent form specific to the qualitative research. Here, the term "intervention participants" includes all intervention participants, and "FGD participants" includes only the views of intervention participants who also participated in a focus group. Each FGD lasted 1 to 1.5 hours. The average age of all intervention participants was 41 years, and they had spent an average of 4 years in the HIV/AIDS field. As Table 1 shows, the demographic characteristics of the FGD subset and the full intervention cohort were generally similar, suggesting that the FGD subset was broadly representative of the larger group.

Below we first explore the various themes from the survey and the FGDs, including participant attitudes toward the major 
components of the intervention. We then describe the impact on self-study in relation to the modifying factors that influence learning behaviors, one of the key components to the lateral learning framework. Finally, we analyze the impact the intervention had on knowledge and self-efficacy.

\section{Views of the Intervention}

Similar to the results of mCME V.1.0, participants reported positive views of the intervention and of CME in general for mCME V.2.0 [17]. Of the 48 intervention participants, 45 (94\%) agreed or strongly agreed with the statement "I believe CME is important" and 43 (90\%) agreed or strongly agreed that text messages can provide motivation to study for CME accreditation (Figure 2). Additionally, 41 of the $48(85 \%)$ intervention participants who accessed all 3 components of the intervention rated their experience as "very satisfying" or "somewhat satisfying."

Intervention participants commented on their experiences with the 3 main components of the intervention: the daily quizzes, the daily readings that corresponded to the quiz question, and the HMU courses. Figure 2 shows additional survey data indicating the percentage of participants who agreed or strongly agreed with Likert-scale questions from the endline survey. 
Table 1. Demographic characteristics and intervention behaviors of Mobile Continuing Medical Education Project (mCME V.2.0) trial participants.

\begin{tabular}{|c|c|c|}
\hline Characteristics & $\begin{array}{l}\text { Intervention participants } \\
(\mathrm{n}=48)\end{array}$ & $\begin{array}{l}\text { Focus group participants } \\
(\mathrm{n}=30)\end{array}$ \\
\hline \multicolumn{3}{|l|}{ Sex, $n(\%)$} \\
\hline Male & $19(40)$ & $11(37)$ \\
\hline Female & $29(60)$ & $19(63)$ \\
\hline \multicolumn{3}{|l|}{ Research site, $\mathrm{n}(\%)$} \\
\hline Thái Nguyên & $18(38)$ & $10(33)$ \\
\hline H i Phòng & $17(35)$ & $10(33)$ \\
\hline Qu ng Ninh & $13(27)$ & $10(33)$ \\
\hline Age (years), mean (SD) & $41.1(8.8)$ & $40.43(8.7)$ \\
\hline Years working in HIV/AIDS health sector, mean (SD) & $4.3(4.8)$ & $5.20(5.2)$ \\
\hline \multicolumn{3}{|l|}{ Clinical degree, $n(\%)$} \\
\hline MD & $20(42)$ & $13(43)$ \\
\hline Mid-level provider & $28(58)$ & $17(57)$ \\
\hline \multicolumn{3}{|c|}{ Text message response rate ${ }^{a}$ during study, by location, $n(\%)$} \\
\hline \multicolumn{3}{|l|}{ Thái Nguyên } \\
\hline High & $13(72)$ & $5(50)$ \\
\hline Low & $5(28)$ & $5(50)$ \\
\hline \multicolumn{3}{|l|}{ H i Phòng } \\
\hline High & $11(65)$ & $5(50)$ \\
\hline Low & $6(35)$ & $5(50)$ \\
\hline \multicolumn{3}{|l|}{ Qu ng Ninh } \\
\hline High & $10(77)$ & $7(70)$ \\
\hline Low & $3(23)$ & $3(30)$ \\
\hline \multicolumn{3}{|l|}{ Hanoi Medical University course use during study, n (\%) } \\
\hline Ever & $32(67)$ & $19(63)$ \\
\hline Never & $16(33)$ & $11(37)$ \\
\hline \multicolumn{3}{|l|}{ Daily readings access during study, $n(\%)$} \\
\hline Ever & $41(85)$ & $22(73)$ \\
\hline Never & $7(15)$ & $8(27)$ \\
\hline \multicolumn{3}{|l|}{ Hours per week spent on medical self-education, $\mathrm{n}(\%)$} \\
\hline 0 & $1(2)$ & $1(3)$ \\
\hline $1-2$ & $26(54)$ & $17(57)$ \\
\hline $2-4$ & $9(19)$ & $6(20)$ \\
\hline $4-7$ & $7(15)$ & $3(10)$ \\
\hline$\geq 8$ & $5(10)$ & $3(10)$ \\
\hline \multicolumn{3}{|l|}{ Number of patients seen per day on average, $n(\%)$} \\
\hline $0-9$ & $23(48)$ & $15(50)$ \\
\hline $10-19$ & $7(15)$ & $5(17)$ \\
\hline $20-29$ & $8(17)$ & $4(13)$ \\
\hline $30-39$ & $4(8)$ & $2(7)$ \\
\hline$\geq 40$ & $6(12)$ & $4(13)$ \\
\hline
\end{tabular}

${ }^{\mathrm{a}}$ For response rates, high refers to those $\geq 85 \%$ for Thái Nguyên, $\geq 82 \%$ for H i Phòng, and $\geq 77 \%$ for Qu ng Ninh. 
Figure 2. Sample of Likert-scale responses from Mobile Continuing Medical Education Project (mCME V.2.0) trial intervention participants in the endline survey showing the proportion of those who agreed or strongly agreed with the statements shown (standard error bars with $95 \% \mathrm{CI}$ ). Importantly, for questions pertaining to the daily readings and the Hanoi Medical University (HMU) courses, we excluded the responses from participants who never accessed those intervention components. CME: continuing medical education; SMS: short message service.

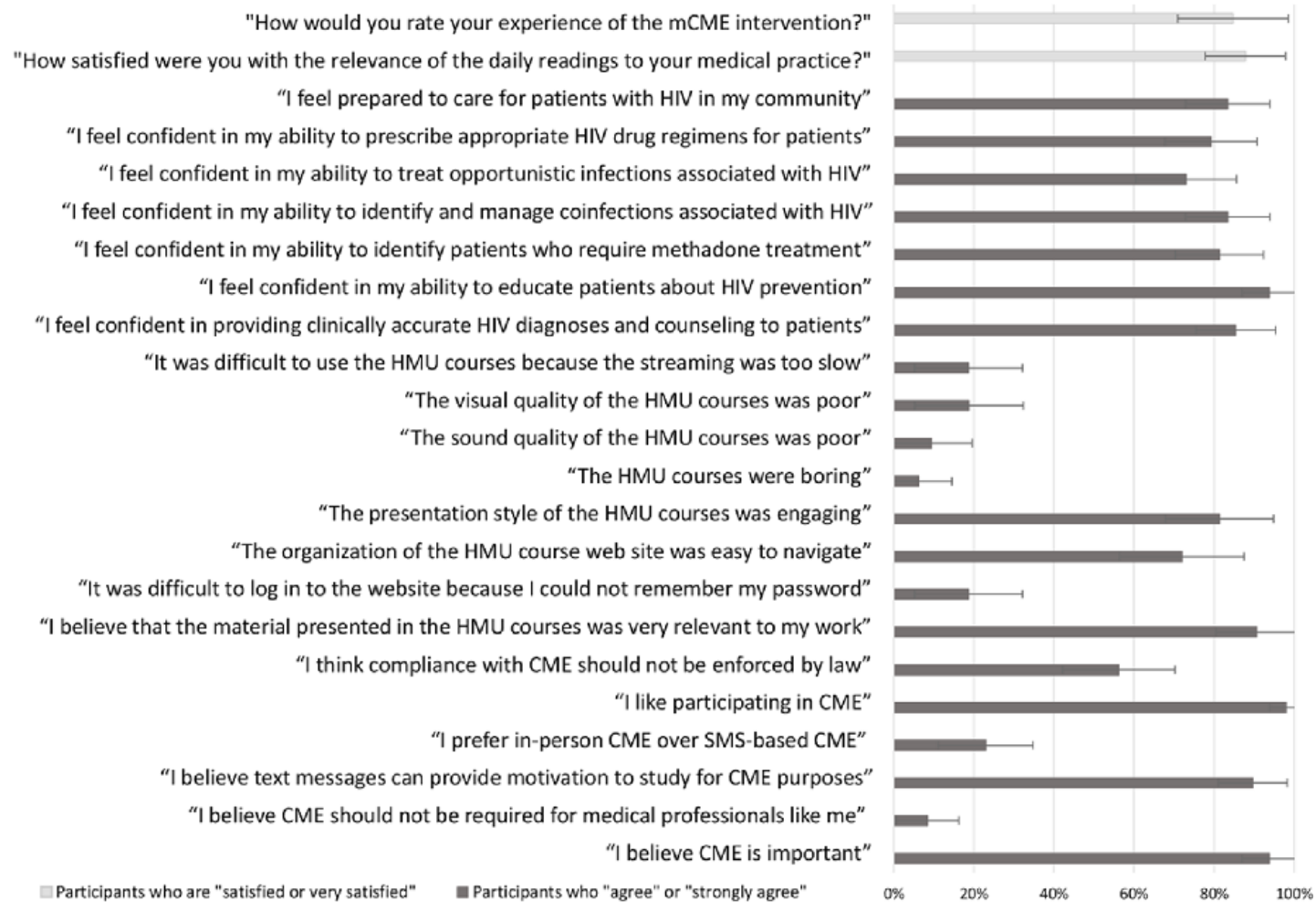

\section{Daily Quizzes}

Most FGD participants liked the daily quizzes, finding them to be convenient, relevant, and informative. This is consistent with daily quiz response rates during the intervention, which averaged $81.9 \%$ (118/144 daily quizzes) across 3 sites [19]. A few participants even wished that the intervention would continue; one commented that, "I quite miss the daily quizzes now that the intervention is over" (participant in $\mathrm{H}$ i Phòng) and another said, "There have been no quizzes in the last 2 weeks and I miss them" (participant in Qu ng Ninh). Remarking on the convenience of the daily quizzes, one participant said, "I feel satisfied because it is clear whether I have answered right or wrong" (participant in Qu ng Ninh). Several participants reported that the daily quizzes led them to access educational materials to learn more about the topic area; 1 participant noted that they "encourage us to search for knowledge to be able to answer the questions - we had to read books or access online materials" (participant in Thái Nguyên).

Although most liked the quizzes, FGD participants commented that the two main drawbacks of the daily quiz were the formatting and system errors. Referring to phonetic markings and clarity, one person said, "I think the contents of the messages were not clear: choice $\mathrm{a}$ and $\mathrm{b}$ were sometimes put together in one line with no punctuation" (participant in Thái Nguyên). All participants in the FGD in Qu ng Ninh agreed that the texts on the phone were too short, which affected their ability to understand what was being asked. Finally, participants at all 3 sites mentioned that there were sometimes system errors with the messages. One participant said, "Sometimes I chose the right answer but the system said I was wrong" (participant in $\mathrm{H}$ i Phòng) and another said, "Some questions are vague, for example a question has many [correct] answers" (participant in Qu ng Ninh). In this particular case, there was indeed one instance in which the programmers listed the wrong answer for a daily quiz; however, the claim that some quizzes had multiple correct answers was untrue.

Notably, most participants suggested that texts be sent in the morning and 24 hours be allotted to answer each SMS text message. One participant said that:

The timing of the messages in the afternoon is not reasonable. I had no time to search for more knowledge, since we were often busy in the afternoon at work, and at home we were too tired to research more. [participant in Thái Nguyên]

We intentionally changed the timing of when the daily quiz was sent each day about halfway through the trial to test the impact of timing on the response rate. Most participants agreed that the timing of the messages (1:00 PM) negatively affected their ability to respond or seek out answers from provided resources. Importantly, although participants strongly protested against afternoon daily messages as opposed to morning messages, the response rate and correct answer rate was not significantly different between the 2 time points (Multimedia Appendix 2).

\section{Daily Readings}

Of the 3 intervention components, the daily readings had the lowest rates of utilization. The intervention participants accessed, on average, $18.1 \%$ (26/144) of the daily readings that 
they had received over the course of the intervention [19]. Many explained that the daily readings didn't have enough in-depth information to cover complex topics. One participant elaborated:

I also think the contents in the links were not enough...when I accessed the links I didn't understand completely. I still had questions and had to find other resources. If one doesn't have enough knowledge on HIV then it would be difficult to understand contents of the link only. [participant in Thái Nguyên]

For some, the length of the readings was sufficient and time efficient, but other participants sought more in-depth knowledge to gain deeper insight into the topic area.

Some participants found the daily readings to be a quick way to access information related to the daily quizzes. One participant noted that the daily readings in concert with the daily quizzes improved understanding:

Receiving daily messages probably helps me a lot, since I've just started [providing] ARV treatment for 3 months. It helps me in reading materials and providing information, thus enabling my self-study. [participant in Thái Nguyên]

Another said that:

The links to the daily readings are great because they provide immediate answers. [participant in $\mathrm{Qu} n$ Ninh]

Of the participants who accessed the daily readings, $88 \%$ (35/41) said that they were satisfied or very satisfied with the relevance of the daily readings to their medical practice (Figure 2). Despite these noted benefits, many participants complained that the daily readings were insufficient to improving their medical knowledge. One participant said simply that:

The contents of the daily readings are insufficient, especially for case questions. [participant in $\mathrm{Qu} \mathrm{ng}$ Ninh]

\section{Hanoi Medical University Courses}

For the primary end point of this study, we observed that the intervention participants accounted for $83.2 \%$ of the total course use across intervention and control groups (134/161 total times accessed by all users), and intervention participants were significantly more likely than the control participants to ever access the HMU courses (relative risk 2.3, 95\% CI 1.4-3.8) [18]. Few participants regularly accessed the HMU courses, but most of the intervention participants who ever accessed the courses thought the lectures were engaging $(26 / 32,81 \%)$ and relevant $(29 / 32,91 \%)$. One participant commented that:

If it was a topic I'm interested in then I'd watch it carefully. Some contents were very in-depth... [and the] assessment was very interesting, since it allowed me to see how much I could do, if I am progressing or not. [participant in Thái Nguyên]

Most approved of the quality of the courses in terms of content, sound, visual elements, and navigation, according to the endline survey (Figure 2).
Reasons for not using the HMU courses included the participant's lack of availability, topic relevance, and motivation. Speaking to why someone wouldn't take the course, one person noted that:

Some knowledge I have already owned and have been directly trained, which makes it boring although I really like studying....Also, for the same lectures, reading documents only takes me 15-20 minutes, while listening to lecturer is too time consuming and I am sometimes busy, although it helps me gain more knowledge. [participant in Qu ng Ninh]

Another noted availability and course quality as deterrents:

I rarely use the HMU courses because the lectures are lengthy and unattractive despite being useful. First, they are just speeches or slides. Second, although they are beneficial, sometimes I am busy for 1, 2 days or even a week so I may forget to answer and there is no reminder from the system. [participant in Qu ng Ninh]

Many also suggested in the FGDs that the HMU lectures be updated to reflect current treatment guidelines; as one participant commented:

I hoped the knowledge would be updated according to the current treatment knowledge. At least we should be able to know the current possibility in treatment so we could give suitable consultation for patients. [participant in Thái Nguyên]

Accessing the lectures on their mobile phones was also challenging. One person said, "The speed of loading links is quite slow for phones with low configuration, making it difficult to access" (participant in Qu ng Ninh) and another noted that, "The online training provided by HMU loaded slowly on mobile phones despite a good Wi-Fi connection" (participant in Thái Nguyên).

Finally, several noted the limitations of mCME versus traditional CME when discussing the online courses. Many participants agreed that e-learning is the most convenient method. One participant said that:

This approach is very convenient, aiming to the majority of learners, any type of individual and convenient for community-based health staff. [participant in Thái Nguyên]

However, several participants expressed more ambivalence toward online training:

This method does not have interaction between teachers and students so I feel unsatisfied because I cannot ask questions. But this method enables me to choose whichever part I like to study. [participant in Qu ng Ninh]

Others suggested that direct training be combined with mCME:

[With mCME], we get the convenience and can get access to it anytime, but especially in the treatment aspect, direct training with feedback would be more efficient and help keep a longer memory. Therefore, 
I suggest that online learning and direct training should be combined. [participant in Thái Nguyên]

\section{Impact on Self-Study: Modifying Factors That Influenced Learning Behaviors}

Our study results indicate that, compared with pretrial surveys, participants in the intervention group at endline reported higher levels of self-study through reference to medical textbooks, colleagues, online research, medical specialty websites, Vietnamese treatment guidelines, and scientific literature than their control group counterparts [18]. In the focus groups, participants raised several factors that influenced their decision to engage in self-study beyond memorizing the answer from the daily multiple-choice quiz. Among these factors were their time or availability, relevance of the subject matter to their profession, convenience of the intervention, perceived quality of the HMU and daily readings resources, individual-level subject matter expertise, technological literacy, and motivation to learn (Table 2).

Each of these factors fits within the lateral learning framework outlined in Figure 1. Table 2 provides exemplar quotes detailing the various factors that influenced participants' decisions to engage in this lateral learning, or learning beyond rote memorization of the SMS text message.

Participant responses to the cues to action (SMS text message quizzes, course reminders, and performance feedback) were contextual, and the modifying factors listed in Figure 1 either aided in self-study or inhibited it. For example, participants studied more if they found the material to be professionally relevant, and did not study if they found the inverse.

Table 2. Quote excerpts from focus group discussions illustrating modifying factors in the decision to engage in lateral learning, May 2017.

\begin{tabular}{|c|c|}
\hline Factor & Quote \\
\hline \multirow[t]{3}{*}{ Time or availability } & Honestly I don't have much time so I would not access [additional materials]. \\
\hline & $\begin{array}{l}\text { Q: Is there anybody who answered without checking any source? All: Yes, when we are too } \\
\text { busy. }\end{array}$ \\
\hline & $\begin{array}{l}\text { There are other things to do apart from studying. Actually, there are very few people who have } \\
\text { time to participate in the courses at home, and studying when working often gets interrupted. }\end{array}$ \\
\hline \multirow[t]{3}{*}{ Professional relevance } & $\begin{array}{l}\text { I would spend more time studying work-related topics, I researched more and often got a high } \\
\text { score; other than that I would skip. }\end{array}$ \\
\hline & The [materials] are directly related to my work, so I need to study to improve my knowledge. \\
\hline & $\begin{array}{l}\text { I believe that people directly treating patients would know more than us, so for those who do not } \\
\text { know much about HIV/AIDS like us, reading is very important. }\end{array}$ \\
\hline \multirow[t]{3}{*}{ Convenience } & I could study at home. There is no need to go to class, so it is time and cost effective. \\
\hline & $\begin{array}{l}\text { All: Studying on our phones is more convenient because it is not possible to bring our laptops } \\
\text { along all of the time. }\end{array}$ \\
\hline & $\begin{array}{l}\text { The most beneficial thing for us working at medical centers is that we can study anywhere, } \\
\text { without having to attend classes; it is suitable for those who live far away from the training centers. }\end{array}$ \\
\hline
\end{tabular}

Perceived quality of resources The links provide more information from research, which is very useful. Participant location Thái Nguyên $\mathrm{H}$ i Phòng

Qu ng Ninh Thái Nguyên Thái Nguyên Thái Nguyên $\mathrm{H}$ i Phòng

Qu ng Ninh

Thái Nguyên

Some lectures were not updated, although the official documents and national treatment guides are changed frequently.

The current explanation in the links was short and insufficient; there should be more information Thái Nguyên so we wouldn't have to access other sites.

Subject matter expertise

Technology literacy or accessibility

Motivation
Unlike those of you who have been in this program for one year and have experience and knowledge, I am totally new to this field and I need to search for information.

People who are new to this information will be more motivated to study. I have already been trained about this before so I don't actively participate in the courses, although I think they are useful for me.

The password is hard to remember. Sometimes I have to type it from the beginning.

My limitation would be my bad eyesight. I would only read the links if I was on the computer. It may take 1 or 2 weeks for us to remember the phone number [text message] of the program.

I like it best when having group discussion, sending the answer, and then receiving "Congratulations" on giving the right answer.

If studying time is taken into account to decide whether or not one could receive a certificate, I Qu ng Ninh will have a purpose and be more motivated to study.

When I have answered too many quizzes and my score is low compared to the group average, I H i Phòng will read the daily readings to gain more knowledge.
Qu ng Ninh

Thái Nguyên

Qu ng Ninh

Qu ng Ninh

Qu ng Ninh

Thái Nguyên

H i Phòng

Qu ng Ninh 
One participant said, "If I need the knowledge at that moment, I will be more motivated to study" (participant in Qu ng Ninh), but another commented that, "I would spend more time studying work-related topics, I researched more and often got high score; other than that I would skip [questions]" (participant in Thái Nguyên). Similarly, whether they viewed mCME as convenient affected their study behaviors. One participant said that:

The most beneficial thing for us working at medical centers I think is that it can be studied anywhere, without having to attend classes, and it is suitable for those who live far away from the training center. [participant in Thái Nguyên]

A counterpart said:

Actually, there are very few people who have time to participate in the courses at home, and studying when working often gets interrupted. Sometimes it is possible to read the entire lectures but sometimes I have to turn it off after having read for only 1 or 2 minutes. [participant in Qu ng Ninh]

Ultimately, these modifying factors boil down to the individual participant. One health professional from Thái Nguyên succinctly summarized, noting that "Compared to direct training, I think online learning is very good, with the condition that the learner has the will to learn."

\section{Impacts of the Intervention on Self-Study and Medical Knowledge}

The mCME V.2.0 intervention significantly increased self-study behaviors, leading to improved HIV medical knowledge and perceived skills, and high levels of job satisfaction [18]. In particular, it was the unique combination of these multiple components of the intervention-the cues to action (daily quizzes and individual or peer feedback) and links to self-study resources (daily readings and HMU courses) - that was appealing to participants. When asked which of the components was most useful, nearly half chose all 3 , rather than selecting only one.

\section{Impact on HIV Knowledge}

In mCME V.2.0, intervention participants accessed HMU courses and daily readings significantly more than the control group did, and response rates to the daily quizzes remained high throughout the trial. This resulted in a significant difference in examination scores between intervention and control participants [18]. Of the 48 intervention participants, $83 \%(n=40)$ felt that they were better prepared to care for patients with HIV in their communities, compared with $67 \%(\mathrm{n}=32)$ at baseline. In the FGDs, participants reported similarly that the intervention improved their knowledge of HIV. One participant said that, "At first I didn't know much, but after that I still needed to read more materials and use the internet to improve my knowledge" (participant in Thái Nguyên). Another noted that, "The benefit is that [the quizzes] motivated me to search for information in order to answer questions in the field that I do not have much knowledge about" (participant in $\mathrm{H}$ i Phòng).

\section{Impact on HIV Feelings of Self-Efficacy}

Our intervention did not evaluate clinical skills, but we did ask participants to comment on their own abilities pertaining to HIV care. Figure 2 illustrates additional self-assessment data of HIV knowledge and self-efficacy. Of particular note, 85\% (41/48) of intervention participants reported that they either agreed or strongly agreed with the statement "I feel confident providing clinically accurate HIV diagnoses and counseling to patients," and 94\% (45/48) agreed or strongly agreed with the statement "I feel confident in my ability to educate patients about HIV prevention" (Figure 2). However, none of these self-assessments different significantly from the control group, with the exception of the statement "I feel confident in my ability to appropriately identify patients who require methadone treatment." One FGD participant summed up these views, saying that, "The most important benefit is that [the courses] increase our knowledge and help us become more confident" (participant in $\mathrm{H}$ i Phòng).

\section{Discussion}

\section{Principal Findings}

Data from this randomized controlled trial among HIV clinicians in Vietnam may suggest that a mobile CME intervention is both effective at improving medical knowledge and self-study behaviors, and acceptable by trial participants. Participants reported in our postintervention survey and FGDs that they liked the 3 components of the intervention: the daily quizzes, the daily readings, and the HMU online courses. FGD participants noted that the daily quizzes encouraged them to seek out answers and learn on a daily basis, but also commented that clarity of the messaging and the timing of the messages were sometimes an issue. HMU course utilization rates were significantly higher in the intervention group, but participants noted that the quality, format, and loading time of the HMU courses precluded additional use. The HMU courses themselves were unpopular; participants' use of this resource was low, and public health officials should address feedback on these resources when developing new content for their platforms. The daily readings were not well used during the intervention; some participants found them to be too short to provide sufficient information. However, in the context of mCME, many noted that the readings were helpful in that they provided immediate and accurate answers to the daily quiz questions. We conclude that the intervention was acceptable, was convenient, and helped improve health professionals' knowledge of HIV treatment and care in Vietnam within this population of HIV providers.

Although we showed the intervention to improve medical knowledge, disaggregating the 3 components of the intervention to understand which was the most influential remains a challenge. A medical degree, or even CME, given over SMS text messaging is not sufficient, and content without practical training is not sufficient for health professionals. We posit that it was not the SMS text messages, but rather the stimulus that they provided to seek out answers and improve their self-study via digital and interprofessional resources, that was responsible for the improvement in medical knowledge. The survey and FGD data presented in this analysis supports this hypothesis, and we also explored this further in a separate quantitative 
analysis of the factors that led participants to engage in self-study behaviors [19].

Many factors interrelated to facilitate or prevent self-study in this population, as outlined in Figure 1 and Table 2. For example, the convenience of $\mathrm{mCME}$, combined with the feeling that the topic area was professionally relevant, could have motivated a participant to study. Inversely, lack of free time coupled with the feeling that the participant was already an expert in the subject matter could have discourage one from doing so. These factors, considered both individually and with others, may have been important influencers in a participant's decision to engage in lateral learning during the intervention period.

When considering the variables that influence a clinician's decision to seek out in-depth information, we must consider these aforementioned variables, as well as the larger framework of the HBM. This model posits that an individual's perceived severity of disease and perceived susceptibility to disease, along with cues to action and moderating variables, all contribute to the decision-making process of whether to engage in a health behavior [20,21]. Applied to our research setting, the HBM can be used to consider the different factors that influence a clinician's decision to engage in lateral learning (Figure 1). Following this framework, intervention participants chose to both engage and not engage in lateral learning, based on the personal value placed on the modifying factors and their perspectives on the need and importance of CME. In this research study, the intervention group had a larger change in performance between baseline and endline examinations than did controls, who did not have any of the cues to action listed in this model [18]. Past research is consistent with the findings of this analysis, which postulate that, ultimately, medical professionals must find the internal motivation to learn and must view learning both as beneficial to their practice and as something they are capable of doing [22,23].

Multiple theories have been put forward in the field of CME to enhance learning, and these theories need to be applied when developing distance CME programs in the future [24]. This research intervention attempted to answer the question of whether CME might be delivered at a distance, and our conclusion is that this is a viable method, provided that we employ behavior change learning models rather than purely educational ones. Our research framework considered the HBM but adapted it to a pedagogical setting, providing public health professionals with the successful structure that could be repeated and adapted to future iterations of this program at a national scale. Additional quantitative research is recommended in this area to support generalizability to other settings and populations, and to further explore the modifying factors that ultimately influence access, use, and learning.

\section{Limitations}

Our study had several limitations. With only 106 health professionals enrolled, our sample size was relatively small, which suggests that this research should be repeated at a larger scale to further inform precise impact measures. However, it is important to note that we selected participants via rigorous sampling and randomization methods, and we were able to capture nearly all eligible participants across the 3 provinces. Additionally, participants in qualitative research are always subjected to social desirability bias, which could mean that the statements made may not accurately reflect their actions so much as their desire to appear to be good students. We mitigated this by triangulating our quantitative and qualitative results and including opinions of only those who ever accessed the components of the intervention when reporting on their views of the intervention. And lastly, our research measured HIV medical knowledge, which is related to but not the same as clinical practice. Future research should explore the modifying factors that affect learning and measure whether CME programs improve clinical diagnoses, treatment, and general performance.

\section{Conclusion}

In this randomized controlled trial, we have proven that the intervention (1) improved self-study behaviors, (2) improved medical knowledge, and (3) was acceptable to the target population. This mixed-methods analysis demonstrated that the intervention was easy to use, convenient, and relevant to the participants' work. Factors such as topic relevance, subject matter expertise, and availability of high-quality resources affected participants' decisions to access additional resources. If public health officials choose to scale up this platform to the national level, future programs may consider the lateral learning framework as part of a successful strategy to engage in higher learning and truly improve medical knowledge. mCME was well liked, inexpensive, and cost effective, and thus merits consideration for nationwide scale-up. If implemented, mCME has the potential to improve the medical knowledge of health professionals across multiple disciplines.

\section{Acknowledgments}

This study was supported by an R21 grant from the US National Institutes of Health/Fogarty International Center, Bethesda, MD, USA (R21TW009911). We thank Rich Feeley, former Interim Chair of the Department of Global Health at the Boston University School of Public Health for his strong support for our work in Vietnam. We are especially grateful to all the HIV clinicians who participated in the mCME study in Thái Nguyên, Qu ng Ninh, and H i Phòng provinces.

\section{Conflicts of Interest}

None declared. 


\section{Multimedia Appendix 1}

Study design of mCME V.2.0 (November 2016 to May 2017).

[PNG File, 628KB-Multimedia Appendix 1]

\section{Multimedia Appendix 2}

Impact of timing of daily quiz on response rate, correct answer rate, and use of daily readings.

[PNG File, 12KB-Multimedia Appendix 2]

\section{References}

1. Government of Vietnam. Circular 22/2013/tt-Byt: Guide the continuous training for medical officers. Dorval, QC: Global-Regulation Inc; 2019. URL: https://www.global-regulation.com/translation/vietnam/2955560/ circular-22-2013-tt-byt\%253a-guide-the-continuous-training-for-medical-officers.html [accessed 2019-02-15] [WebCite Cache ID 76Cp60ruc]

2. van der Velden T, Van HN, Quoc HNV, Van HN, Baron RB. Continuing medical education in Vietnam: new legislation and new roles for medical schools. J Contin Educ Health Prof 2010;30(2):144-148. [doi: 10.1002/chp.20068] [Medline: 20564715]

3. Tran TMO, Khuong AG, Hoang P, Nguyen KP, Ong TD, Krishna H. Public Hospital Governance in Asia and the Pacific. Comparative Country Studies. Geneva, Switzerland: World Health Organization; 2015. Public hospital governance in Viet Nam: a case study in two provinces URL: http://iris.wpro.who.int/bitstream/handle/10665.1/11361/9789290617112 eng. pdf [accessed 2019-02-15] [WebCite Cache ID 76CpDKO1o]

4. Lam JA, Dang LT, Phan NT, Trinh HT, Vu NC, Nguyen CK. Mobile health initiatives in Vietnam: scoping study. JMIR Mhealth Uhealth 2018 Apr 24;6(4):e106 [FREE Full text] [doi: 10.2196/mhealth.8639] [Medline: 29691214]

5. Fordis M, King JE, Ballantyne CM, Jones PH, Schneider KH, Spann SJ, et al. Comparison of the instructional efficacy of internet-based CME with live interactive CME workshops: a randomized controlled trial. JAMA 2005 Sep 07;294(9):1043-1051. [doi: 10.1001/jama.294.9.1043] [Medline: 16145024]

6. Rossaro L, Tran TP, Ransibrahmanakul K, Rainwater JA, Csik G, Cole SL, et al. Hepatitis C videoconferencing: the impact on continuing medical education for rural healthcare providers. Telemed J E Health 2007 Jun;13(3):269-277. [doi: $\underline{10.1089 / \text { tmj.2006.0050] [Medline: } 17603829]}$

7. Hashmi NR, Khan SA. Interventional study to improve diabetic guidelines adherence using mobile health (m-Health) technology in Lahore, Pakistan. BMJ Open 2018 Dec 31;8(5):e020094 [FREE Full text] [doi: 10.1136/bmjopen-2017-020094] [Medline: 29858411]

8. Latifi K, Lecaj I, Bekteshi F, Dasho E, Doarn CR, Merrell RC, et al. Cost-benefit analysis on the use of telemedicine program of Kosova for continuous medical education: a sustainable and efficient model to rebuild medical systems in developing countries. Telemed J E Health 2011 Dec;17(10):757-762. [doi: 10.1089/tmj.2011.0102] [Medline: 22011053]

9. Hipple B, Nabi-Burza E, Hall N, Regan S, Winickoff JP. Distance-based training in two community health centers to address tobacco smoke exposure of children. BMC Pediatr 2013 Apr 17;13:56 [FREE Full text] [doi: 10.1186/1471-2431-13-56] [Medline: 23594832]

10. Ricci MA, Caputo MP, Callas PW, Gagne M. The use of telemedicine for delivering continuing medical education in rural communities. Telemed J E Health 2005 Apr;11(2):124-129. [doi: 10.1089/tmj.2005.11.124] [Medline: 15857252]

11. Zolfo M, Iglesias D, Kiyan C, Echevarria J, Fucay L, Llacsahuanga E, et al. Mobile learning for HIV/AIDS healthcare worker training in resource-limited settings. AIDS Res Ther 2010 Sep 08;7:35 [FREE Full text] [doi: 10.1186/1742-6405-7-35] [Medline: 20825677]

12. Dunleavy G, Nikolaou CK, Nifakos S, Atun R, Law GCY, Tudor Car L. Mobile digital education for health professions: systematic review and meta-analysis by the digital health education collaboration. J Med Internet Res 2019 Feb 12;21(2):e12937 [FREE Full text] [doi: 10.2196/12937] [Medline: 30747711]

13. Alipour S, Jannat F, Hosseini L. Teaching breast cancer screening via text messages as part of continuing education for working nurses: a case-control study. Asian Pac J Cancer Prev 2014;15(14):5607-5609 [FREE Full text] [Medline: 25081673]

14. Alipour S, Moini A, Jafari-Adli S, Gharaie N, Mansouri K. Comparison of teaching about breast cancer via mobile or traditional learning methods in gynecology residents. Asian Pac J Cancer Prev 2012;13(9):4593-4595 [ㅌREE Full text] [Medline: 23167386]

15. Battat R, Jhonson M, Wiseblatt L, Renard C, Habib L, Normil M, et al. The Haiti Medical Education Project: development and analysis of a competency based continuing medical education course in Haiti through distance learning. BMC Med Educ 2016 Oct 19;16(1):275 [FREE Full text] [doi: 10.1186/s12909-016-0795-x] [Medline: 27760535]

16. Gill CJ, Le Ngoc B, Halim N, Nguyen Viet H, Larson Williams A, Nguyen Van T, et al. The mCME Project: a randomized controlled trial of an SMS-based continuing medical education intervention for improving medical knowledge among Vietnamese community based physicians' assistants. PLoS One 2016;11(11):e0166293 [FREE Full text] [doi: 10.1371/journal.pone.0166293] [Medline: 27861516] 
17. Sabin LL, Larson Williams A, Le BN, Herman AR, Viet Nguyen H, Albanese RR, et al. Benefits and limitations of text messages to stimulate higher learning among community providers: participants' views of an mHealth intervention to support continuing medical education in Vietnam. Glob Health Sci Pract 2017 Dec 27;5(2):261-273 [FREE Full text] [doi: 10.9745/GHSP-D-16-00348] [Medline: 28655802]

18. Gill CJ, Le NB, Halim N, Chi CTH, Nguyen VH, Bonawitz R, et al. mCME project V.2.0: randomised controlled trial of a revised SMS-based continuing medical education intervention among HIV clinicians in Vietnam. BMJ Glob Health 2018;3(1):e000632 [FREE Full text] [doi: 10.1136/bmjgh-2017-000632] [Medline: 29527350]

19. Nofal MR, Halim N, Le BN, Sabin LL, Larson Williams A, Bonawitz R, et al. Unpacking the "black box": how an SMS-based continuing medical education intervention improved medical knowledge among HIV clinicians in Vietnam. Glob Health Sci Pract 2018 Dec 27;6(4):668-679 [FREE Full text] [doi: 10.9745/GHSP-D-18-00298] [Medline: 30591575$]$

20. Strecher V, Rosenstock I. The health belief model. In: Baum A, Newman S, Weinman J, West R, McManus C, editors. Cambridge Handbook of Psychology, Health and Medicine. Cambridge, UK: Cambridge University Press; 1997:113-117.

21. Rosenstock IM, Strecher VJ, Becker MH. Social learning theory and the health belief model. Health Educ Q 1988;15(2):175-183. [Medline: 3378902]

22. Pelaccia T, Viau R. Motivation in medical education. Med Teach 2017 Feb;39(2):136-140. [doi: 10.1080/0142159X.2016.1248924] [Medline: 27866457]

23. Stegers-Jager KM, Cohen-Schotanus J, Themmen APN. Motivation, learning strategies, participation and medical school performance. Med Educ 2012 Jul;46(7):678-688. [doi: 10.1111/j.1365-2923.2012.04284.x] [Medline: 22691147]

24. Mann KV. The role of educational theory in continuing medical education: has it helped us? J Contin Educ Health Prof 2004;24 Suppl 1:S22-S30. [doi: 10.1002/chp.1340240505] [Medline: 15712774]

\author{
Abbreviations \\ CME: continuing medical education \\ FGD: focus group discussion \\ HBM: health belief model \\ HMU: Hanoi Medical University \\ mCME: Mobile Continuing Medical Education Project \\ mHealth: mobile health \\ SMS: short message service
}

Edited by G Eysenbach; submitted 28.08.18; peer-reviewed by R Alkoudmani, C Nweneka; comments to author 09.01.19; revised
version received 15.02.19; accepted 17.02.19; published 18.04.19
Please cite as:
Larson Williams A, Hawkins A, Sabin L, Halim N, Le Ngoc B, Nguyen VH, Nguyen T, Bonawitz R, Gill C
Motivating HIV Providers in Vietnam to Learn: A Mixed-Methods Analysis of a Mobile Health Continuing Medical Education
Intervention
JMIR Med Educ 2019;5(1):e12058
URL: $\underline{\text { http://mededu.jmir.org/2019/1/e12058/ }}$
doi: $10.2196 / 12058$
PMID: $\underline{30998220}$

(C)Anna Larson Williams, Andrew Hawkins, Lora Sabin, Nafisa Halim, Bao Le Ngoc, Viet Ha Nguyen, Tam Nguyen, Rachael Bonawitz, Christopher Gill. Originally published in JMIR Medical Education (http://mededu.jmir.org), 18.04.2019. This is an open-access article distributed under the terms of the Creative Commons Attribution License (https://creativecommons.org/licenses/by/4.0/), which permits unrestricted use, distribution, and reproduction in any medium, provided the original work, first published in JMIR Medical Education, is properly cited. The complete bibliographic information, a link to the original publication on http://mededu.jmir.org/, as well as this copyright and license information must be included. 